\title{
Políticas de internacionalização na educação superior: transferência de ideias educacionais
}

\author{
Internationalization policies in higher education: \\ transfer of educational ideas \\ Políticas de internacionalización en la educación superior: \\ transferencia de ideas educativas
}

\author{
MARIALVA MOOG PINTO \\ http://orcid.org/0000-0002-9898-8576 \\ Universidade do Planalto Catarinense \\ Programa de Pós-Graduação em Educação \\ Departamento de Educação \\ Lages, SC, Brasil \\ GILDO VOLPATO \\ https://orcid.org/0000-0001-9167-7559 \\ Universidade do Extremo Sul Catarinense \\ Programa de Pós-Graduação em Educação \\ Departamento de Educação \\ Santa Catarina, SC, Brasil
}

\begin{abstract}
Resumo: O estudo de abordagem qualitativa utiliza-se da análise documental para analisar as políticas sobre internacionalização da educação superior (ES), produzidas por organismos multilaterais e transferidas como políticas avaliativas para a ES no Brasil. Analisou-se a Conferência Mundial sobre ES para o Século XXI (UNESCO, 1998), o relatório do Sistema Nacional de Avaliação da ES (SINAES, 2004); o Plano Nacional de Educação (PNE, 2014); e o Instrumento de Avaliação Institucional Externa (INEP, 2017), e confirmou-se que a Conferência (1998) alavancou as políticas avaliativas atuais para a ES no país.
\end{abstract}

Palavras-chave: Políticas educacionais. Educação superior. Internacionalização.

\begin{abstract}
The qualitative approach study uses documentary analysis to analyze the policies on the internationalization of Higher Education (ES) produced by multilateral organizations and transferred as evaluative policies to bigher education in Brazil. The World Conference on Higher Education for the XXI Century (UNESCO, 1998) was analyzed, the report of the National Higher Education Evaluation System (SINAES, 2004); the National Education Plan (PNE, 2014); and the Instrument of External Institutional Evaluation (INEP, 2017), and it was confirmed that the Conference (1998) leveraged the current evaluation policies in the country.
\end{abstract}

Keywords: Educational policies. Higher Education. Internationalization. 
Resumen: El estudio de enfoque cualitativo utiliza el análisis documental para analizar las politicas de internacionalización de la Educación Superior (ES) producidas por organismos multilaterales y transferidas como políticas evaluativas a la ES en Brasil. Se analizó la Conferencia Mundial de ES para el Siglo XXI (UNESCO, 1998), el informe del Sistema Nacional de Evaluación de la ES (SINAES, 2004); el Plan Nacional de Educación (PNE, 2014); y el Instrumento de Evaluación Institucional ES (INEP, 2017), y se confirmó que la Conferencia (1998) apalancó las políticas de evaluación vigentes para la ES en el país.

Palabras clave: Políticas educativas. Educación universitaria. Internacionalización.

\section{INTRODUÇÃO}

A internacionalização da educação superior (ES) tem sido motivo de debate, tendo em vista as novas exigências avaliativas dos órgãos de controle, tanto na graduação quanto na pós-graduação. São inúmeras as exigências e expectativas colocadas sobre os professores universitários e os pesquisadores que atuam na graduação e na pós-graduação, pois os resultados dos acordos e das produções internacionais acabam potencializando as instituições de educação superior (IES), no sentido de atribuir-lhes poder e referência acadêmica. Cada vez mais os acordos e as relações internacionais, consideradas como princípios acadêmicos de valor, são universalizados. Sendo assim, o processo de globalização impulsionou as políticas de internacionalização e os organismos multilaterais que têm realizado as devidas transferências educacionais.

O conceito de transferência pressupõe a movimentação de ideias e práticas educacionais e a definição de políticas para que elas ocorram entre diferentes localidades. Quando a transferência se refere ao campo educacional, os conselhos elaborados pelas agências multilaterais indicam as ideias que devem ser colocadas em prática para solucionar problemas de outros contextos, sempre acompanhadas do discurso de desenvolvimento.

O tema da internacionalização ganhou importância e o Ministério das Relações Exteriores, com o objetivo de fomentar o debate no Brasil sobre questões de relevo para o desenvolvimento nacional, publicou, em 2012, na coleção Mundo Afora, de no 9 (BRASIL, 2012), com o tema: "Política de internacionalização da universidade", que priorizou dar visibilidade às políticas de internacionalização de inúmeros países ao redor do mundo, visando inspirar as IES nacionais.

A partir da análise da temática em questão e do que temos percebido no âmbito da educação superior, cabe perguntar: como são tomadas as decisões em relação aos critérios e os indicadores de qualidade? As políticas avaliativas externas estão sendo transferidas para os países em desenvolvimento, em geral, e para o Brasil, em particular? 
A presente pesquisa teve como objetivo compreender como as orientações de organismos multilaterais sobre a internacionalização da ES foram incorporadas aos documentos oficiais de regulação da educação superior brasileira, como o Sistema Nacional de Avaliação da Educação Superior (SINAES, 2004), o Plano Nacional de Educação (PNE, 2014-2024) e o Instrumento de Avaliação Institucional Externa (INEP, 2017), com destaque dado ao processo de mobilidade estudantil e de docentes.

Para situar tal problema, apresentaremos brevemente os métodos científicos utilizados no estudo e, em seguida, os encaminhamentos sobre internacionalização da ES, acordados na Conferência Mundial de Educação Superior (1998), coordenada pela Organização das Nações Unidas para a Educação, a Ciência e a Cultura (Unesco), e com a participação de agências internacionais, e os aconselhamentos a serem percorridos pelas IES, em especial, dos países em desenvolvimento. Em seguida, apresentamos as análises realizadas nos documentos oficiais brasileiros que abrem caminhos para os organismos nacionais realizarem os processos comparativos e, logo após, inferimos as possíveis transferências de modelos, critérios e indicadores que passaram a pautar os processos avaliativos da internacionalização da ES no Brasil.

Trata-se de uma pesquisa qualitativa, de cunho interpretativo, que teve como seu principal interesse olhar as possíveis transferências das políticas avaliativas externas sobre a internacionalização da ES para os países em desenvolvimento, em geral, e para o Brasil, em particular. Para o entendimento do objeto deste estudo foi utilizada a análise documental dos seguintes instrumentos, considerados fontes oficiais: a Conferência Internacional para Educação Superior para o Século XXI: Visão e Ação (UNESCO, 1998), e os posteriores textos elaborados para efetivar, no contexto nacional, as decisões das agências internacionais transferidas para os países em desenvolvimento. São eles: o relatório Sinaes de 2004, o PNE (20142024) e o Instrumento de Avaliação Institucional Externa (INEP, 2017).

$\mathrm{Na}$ interpretação dos dados documentais, foram utilizados os princípios da análise de conteúdo, em cotejamento com os autores que abordam o campo das políticas avaliativas nacionais e internacionais.

Realizou-se, ainda, a análise do material verbal transcrito, de textos produzidos nos diferentes contextos. Para a análise de grande volume de texto, utilizou-se o software Iramuteq, que analisa diferentes tipos de dados textuais, como a lexicografia básica, análises multivariadas e análises de similitude, que possibilita identificar o contexto no qual as palavras ocorrem, com um demonstrativo hierárquico do texto. O software utilizado é uma interface do ambiente estatístico do software R, e produziu as figuras 1, 2 e 3 das análises do estudo. 


\section{INTERNACIONALIZAÇÃO DA EDUCAÇÃO SUPERIOR E A UNESCO}

Sabe-se, por meio da pesquisa, que internacionalização pela via da pósgraduação já se constitui um valor no mundo globalizado, há algumas décadas. No entanto, a partir da década de 1990, o ensino de graduação passou a sentir a influência da globalização e foi inserido também no interesse do panorama internacional, conforme aponta Morosini (2006). O fato de a educação ter sido categorizada e regulamentada pela Organização Mundial do Comércio (OMC), como um serviço, corrobora para que haja a internacionalização e a comercialização do ensino superior (DIAS SOBRINHO, 2005).

É importante mencionar e trazer para debate o quanto o tratado de Bolonha ${ }^{1}$ foi capaz de "mexer" com nossas estruturas acadêmicas, práticas pedagógicas e no trabalho de professores e pesquisadores. A União Europeia orientou a política educacional dentro de seu espaço político e, como alega no relatório europeu sobre a qualidade da educação escolar, sua intenção foi criar um clima de diálogo e prover uma sólida base de aprendizado entre os seus membros, no entanto, no nosso entendimento, acabou por fazer mais do que isso. Afinal, como alerta Mello (2011, p. 29):

O Processo de Bolonha não é uma indução reformista meramente formalburocrática das universidades europeias. É um ato político de considerável envergadura; uma ação conjugada entre Estados de relevante significado histórico, que tem por escopo [...] a consolidação de um espaço europeu transnacional de educação superior [...].

A disseminação ou transferência de influências internacionais pode ser entendida de duas formas, a partir dos estudos de Mainardes (2006) e Beeck (2012): a primeira trata do fluxo de ideias por meio de redes políticas e sociais que envolvem a "circulação internacional de ideias", o "empréstimo de políticas", os grupos de consultores que "vendem" as soluções no mercado político e acadêmico por meio de periódicos, livros, conferências e performances de acadêmicos que viajam para vários lugares para expor suas ideias; a segunda refere-se ao patrocínio ou à imposição de algumas "soluções" oferecidas por agências multilaterais que exercem influência sobre o processo de criação de

\footnotetext{
1 O Tratado de Bolonha, cujo nome usado oficialmente é Declaração de Bolonha (1999), foi firmado entre os ministros da Educação de 29 países europeus, com o objetivo de fortalecer e fomentar a ES na Europa. A ideia do documento é garantir a liberdade competitiva e a abertura do ensino superior, facilitando o translado de estudantes, professores e pesquisadores.
} 
políticas nacionais, entre as quais citamos: o Banco Mundial (BM), a Organização para Cooperação e Desenvolvimento Econômico (OCDE), a Unesco e o Fundo Monetário Internacional (FMI).

Segundo Bartell (2003), há diversas formas de internacionalização da ES e algumas delas são: a presença de estudantes estrangeiros por meio de convênios na graduação; o aumento de concessões de pesquisa internacional e projetos internacionais de pesquisa cooperativados; a existência de associações e consultorias internacionais para universidades estrangeiras; universidades públicas e privadas com metas internacionais estabelecidas; cooperação internacional e colaboração em conselhos; e um grau de imersão internacional no currículo, entre outras.

Sabe-se que na segunda metade do século XX, a ES passou para a história como "o período de sua expansão mais espetacular: o número de matrículas de estudantes em escala mundial multiplicou-se mais de seis vezes, de 13 milhões em 1960 a 82 milhões em 1995” (UNESCO, 1998, s.p.), e contando com 207 milhões de estudantes universitários, em 2014 (ONU, 2019). Portanto, falar de ES e de sua internacionalização é tocar em um contingente significativo de pessoas, de instituições e de países envolvidos nesse processo. Uma das questões debatidas pela ONU, já há algumas décadas, é a necessidade da internacionalização da ES para o alcance da qualidade da formação universitária, mas também do cidadão.

A Unesco parece trabalhar numa perspectiva humanista, com um conceito diferente de desenvolvimento se comparada ao Banco Mundial, pois critica a visão que equaciona desenvolvimento humano com desenvolvimento de recursos humanos (MAYOR, 1997). Segundo Mayor (1997, p. 89), a Unesco “[...] olha para os seres humanos não como instrumentos, meios para atingir objetivos econômicos, mas como fins em si mesmo, estando os objetivos econômicos subordinados à sua auto-realização e ao seu bem-estar", o que nesse aspecto a difere também da OCDE. Isso não significa que a Unesco não esteja em contato com as demais agências internacionais que possuem uma visão neoliberal do mercado (Banco Mundial, OCDE, FMI, etc.), e tampouco ausente das discussões elaboradas por essas instituições.

No intuito de entender como foi absorvida a política de internacionalização da ES pelo Brasil, e suas interfaces, aprofundamos nossas leituras e análise em documentos nacionais e internacionais sobre essa premissa, e nos deparamos com o assunto tratado de forma mais sistematizado e explícito pela primeira vez na Conferência Mundial sobre a Educação Superior no Século XXI: Visão e Ação, realizada em Paris, em 1998. A conferência contou com a participação de diversos países, com o principal objetivo de "prover soluções para os desafios e de 
colocar em movimento um processo de profunda reforma na educação superior mundial." O documento que formaliza essa intenção de forma incisiva e detalhada foi elaborado e firmado pelos países participantes.

Antes da Conferência de Paris (1998), a Unesco iniciou uma preparação para esse evento, publicando o Documento de Política para Mudança e Desenvolvimento em Educação Superior (1995). Essa preparação contou com cinco consultas em contextos mundiais que relacionamos a seguir de forma subsequente: Havana (1996), Dacar (1997), Tóquio (1997), Palermo (1997) e Beirute (1998). Nessa preparação, foram estabelecidas as declarações e os planos de ação que, em cada contexto, promoveram diferentes reflexões. Houve o cuidado de preservar as especificidades de cada uma das consultas que foram divulgadas na conferência, em Paris (1998).

Nessa conferência, foram recordados os princípios da Carta das Nações Unidas, a Declaração Universal dos Direitos Humanos, o Pacto Internacional dos Direitos Econômicos, Sociais e Culturais e o Pacto Internacional de Direitos Civis e Políticos, bem como a Declaração Universal dos Direitos Humanos e, em particular, o artigo 26 no $\$ 1$, no qual se declara que "toda pessoa tem o direito à educação" e, ainda, que "a educação superior deverá ser igualmente acessível a todos com base no respectivo mérito" (ONU, 2019, s.p.).

Observou-se, ainda, os princípios básicos da Convenção contra Discriminação em Educação (1960), a qual, pelo artigo $4^{\circ}$, compromete os estados membros a "tornar a educação superior igualmente acessível a todos segundo sua capacidade individual” (UNESCO, 2019).

As recomendações relativas à educação superior foram apontadas pelas principais comissões e conferências, como: a Comissão Internacional em Educação para o Século XXI (1995); a Comissão Mundial sobre Cultura e Desenvolvimento; a 44 e $45^{a}$ sessões da Conferência Internacional de Educação (Genebra, 1994 e 1996); as decisões da 27ª e 29 Conferências Gerais da Unesco.

Quanto às recomendações referentes à situação do pessoal docente em ES, foram referenciadas: a Conferência Mundial sobre Educação para Todos Jomtiên, Tailândia, 1990); Conferência das Nações Unidas sobre Meio-Ambiente e Desenvolvimento (Rio de Janeiro, 1992); Conferência sobre Liberdade Acadêmica e Autonomia Universitária (Sinais, 1992); Conferência Mundial sobre Direitos Humanos (Viena, 1993); Convocação Mundial para o Desenvolvimento Social (Copenhague, 1995); IV Conferência Mundial sobre Mulheres (Beijing, 1995); Congresso Internacional sobre Educação e Informática (Moscou, 1996); Congresso Mundial sobre Educação Superior e Desenvolvimento de Recursos 
Humanos para o Século XXI (Manila, 1997); V Conferência Internacional sobre Educação de Adultos (Hamburgo, 1997); e Agenda para o Futuro sob o Tema 2: Melhorando as condições e qualidade de aprendizagem, que declarou:

\begin{abstract}
Nós nos comprometemos [...] a abrir escolas, faculdades e universidades para estudantes adultos [...] e rogamos à Conferência Mundial sobre Educação Superior (Paris, 1998) que promova a transformação de instituições póssecundárias em instituições de educação permanente e defina do mesmo modo o papel das universidades. (UNESCO, 1998, s.p.).
\end{abstract}

Esses posicionamentos parecem ter apontado para: um nível de consciência de que a educação é um dos pilares fundamentais dos direitos humanos, da democracia, do desenvolvimento sustentável e da paz, e, portanto, deve ser acessível a todos, no decorrer da vida; e de que são necessárias medidas para assegurar a coordenação e cooperação entre os diversos setores - e dentro de cada um deles: entre a educação em geral, técnica profissional secundária e póssecundária, assim como entre universidades, escolas universitárias e instituições técnicas.

Também em 1988, a Constituição Federal do Brasil consolidou a democracia e trouxe consigo o resgate das garantias e liberdades individuais perdidas com o golpe militar (1964-1984). A Constituição (1988) foi e é considerada uma das mais avançadas do mundo na garantia dos direitos sociais em geral e o direito à educação, em particular. $\mathrm{O}$ texto estabelece oito princípios nos quais o ensino deve se basear e prevê no art. 206, inciso VII, que as políticas educacionais da educação superior brasileira "são direcionadas pelo princípio constitucional da garantia de padrão de qualidade” (BRASIL, 1988). Estabelece, ainda, sete responsabilidades para efetivar o compromisso do Estado com a educação, apontando, no art. 207, que garante "autonomia didática, científica, administrativa e de gestão financeira e patrimonial às universidades."

No entanto, ao falar em "qualidade" o documento não se refere à internacionalização na ES, porém, o art. 214 da Constituição Federal estabelece a construção do "plano nacional de educação, de duração decenal, com o objetivo de articular o sistema nacional de educação em regime de colaboração e definir diretrizes, objetivos, metas e estratégias de implementação para assegurar a manutenção e desenvolvimento do ensino" (BRASIL, 1988).

Como parte do acordo que vinha se constituindo nesses grandes eventos internacionais, o Brasil cria, em 2004, o Sistema Nacional de Avaliação da Educação Superior (Sinaes), lei n 10.861/2004, com objetivo de "assegurar o processo nacional de avaliação das IES, dos cursos de graduação e do desempenho acadêmico de seus estudantes" e, por finalidade, melhorar a qualidade da ES. 
Esse processo está relacionado à cultura de avaliação que vem se impondo no Brasil, desde a LDB 9.394/96, como uma das diretrizes da reforma gerencial dos sistemas educacionais, visando aferir sua eficiência e eficácia, com base em testes padronizados em cada uma das etapas de ensino. Sendo assim, o Sinaes visa:

A orientação da expansão da sua oferta, o aumento permanente da sua eficácia institucional e efetividade acadêmica e social e, especialmente, a promoção do aprofundamento dos compromissos e responsabilidades sociais das instituições de educação superior, por meio da valorização de sua missão pública, da promoção dos valores democráticos, do respeito à diferença e à diversidade, da afirmação da autonomia e da identidade institucional. (INEP, 2019, s. p.).

Nesse momento histórico-social e educativo brasileiro, o discurso sobre "uma educação superior de qualidade" e sobre "uma instituição de Educação Superior de excelência" passa a ser difundido e nem sempre questionado (PINTO, 2010). Alguns grupos acadêmicos, no entanto, voltaram-se para o discurso na tentativa de significá-lo. Nesse caso, fazemos referência às pesquisas do Observatório de Educação e da Rede Interinstitucional de Educação Superior (RIES/PUCRS ${ }^{2}$ ).

O Sinaes foi criado para avaliar todos os aspectos que giram em torno desses eixos: ensino, pesquisa, extensão, responsabilidade social, desempenho dos alunos, gestão da instituição, corpo docente, instalações e vários outros aspectos (SINAES, 2004). No entanto, percebe-se que os eixos estão articulados com os acordos estabelecidos anteriormente, em especial, na Conferência Mundial sobre a Educação Superior no Século XXI, em Paris (1998), que menciona em seu preâmbulo "à melhoria relativa à situação de seu pessoal, ao treinamento com base em habilidades, ao desenvolvimento e manutenção da qualidade no ensino, pesquisa e serviços de extensão [...]". Quanto à responsabilidade social, afirma que "as instituições de educação superior devem assegurar a oportunidade para que estudantes desenvolvam suas próprias habilidades plenamente com um sentido de responsabilidade social, educando-os para tornarem-se participantes plenos na sociedade democrática [...]." (art. $7^{\circ}$ ). Orienta, ainda, sobre o envolvimento "dos estudantes em questões que afetem o nível do ensino, o processo de avaliação, a renovação de métodos pedagógicos e programas curriculares no marco institucional vigente, na elaboração de políticas e na gestão institucional" (art.

2

O Observatório de Educação e da Rede Interinstitucional de Educação Superior (RIES/PUCRS) constituído pelas professoras Maria Costa Morosini (PUCRS), Maria Isabel da Cunha (Unisinos), Maristela Dal Pai Franco (UFRGS), Denise Leite (UFRGS), Silvia Isaias (UFSM), que foram incansáveis em investigar os indicadores de qualidade para a ES. 
$\left.10^{\circ}\right)$. E ecoa, muitas vezes, que a qualidade em ES é um conceito multidimensional que deve envolver todas as suas funções e atividades, como "ensino e programas acadêmicos, pesquisa e fomento da ciência, provisão de pessoal, estudantes, edifícios, instalações, equipamentos, serviços de extensão à comunidade e o ambiente acadêmico em geral." (art. 11\%).

A partir da lei do Sinaes, foi elaborado o Instrumento de Avaliação Institucional Externo Presencial e a Distância, que contempla as 10 dimensões determinadas pelo art. $3^{\circ}$ da lei do Sinaes e agrupadas por afinidade em cinco eixos, com indicadores que apresentam elementos de avaliação e os respectivos critérios para sua análise e verificação (INEP, 2017).

No eixo 3, que trata das "políticas acadêmicas", com peso 10 no cálculo avaliativo, estão os indicadores: 3.1 - Políticas de ensino e ações acadêmicoadministrativas para os cursos de graduação; 3.6 - Política institucional para internacionalização, o mais direcionado em seus critérios; e 3.10 - Políticas institucionais e ações de estímulo à produção discente e à participação em eventos - graduação e pós-graduação (INEP, 2017). Vale lembrar que o Inep (2017, p. 38) entende internacionalização como:

[...] programas e ações que inserem a IES no contexto internacional por meio de cooperação com outras instituições, transferência de conhecimento, mobilidade acadêmica de docentes e estudantes, alunos estrangeiros matriculados na IES, oferta de disciplinas em língua estrangeira, estímulo a publicações e participação em eventos internacionais, participação em processos avaliativos internacionais, entre outros.

O indicador 3.6, que direciona a avaliação da IES sobre a política institucional para internacionalização, "apresenta atividades voltadas para programas de cooperação e intercâmbio e é coordenada por um grupo regulamentado, responsável por sistematizar acordos e convênios internacionais de ensino e de mobilidade docente e discente." (INEP, 2017, p. 19).

Em 2014, como disposto e previsto no art. 214 do texto da Constituição Federal (BRASIL, 1998), foi elaborado o PNE, lei no 13.005/2014, com vigência de dez anos. O plano vigente apresenta 20 metas a serem cumpridas nesse período e toma como referência a Pesquisa Nacional por Amostra de Domicílios (PNAD), o censo demográfico e os censos nacionais da educação básica e superior. É nesse documento, mais especificamente na meta 12 , que se pode encontrar as primeiras absorções sobre as políticas transferidas das agências internacionais para o Brasil sobre internacionalização da ES, manifestando o acordo realizado na Conferência em Paris (1998). 
A meta 12, em sua estratégia 12.12, quer "consolidar e ampliar programas e ações de incentivo à mobilidade estudantil e docente em cursos de graduação e pós-graduação, em âmbito nacional e internacional, tendo em vista o enriquecimento da formação de nível superior" (BRASIL, 2014) e a estratégia 13.7 visa:

[...] fomentar a formação de consórcios entre instituições públicas de educação superior, com vistas a potencializar a atuação regional, inclusive por meio de plano de desenvolvimento institucional integrado, assegurando maior visibilidade nacional e internacional às atividades de ensino, pesquisa e extensão. (BRASIL, 2014).

A estratégia 14.9 orienta no sentido de "consolidar programas, projetos e ações que objetivem a internacionalização da pesquisa e da pós-graduação brasileiras, incentivando a atuação em rede e o fortalecimento de grupos de pesquisa." A estratégia 14.10 tem como objetivo "promover o intercâmbio científico e tecnológico, nacional e internacional, entre as instituições de ensino, pesquisa e extensão"; e a estratégia 14.11 visa "ampliar o investimento em pesquisas com foco em desenvolvimento e estímulo à inovação, bem como incrementar a formação de recursos humanos para a inovação, de modo a buscar o aumento da competitividade das empresas de base tecnológica"; a 14.12 quer "ampliar o investimento na formação de doutores de modo a atingir a proporção de 4 (quatro) doutores por 1.000 (mil) habitantes"; e a estratégia 14.13 pretende "aumentar qualitativa e quantitativamente [...] a competitividade internacional da pesquisa brasileira, ampliando a cooperação científica com empresas, Instituições de Educação Superior - IES e demais Instituições Científicas e Tecnológicas". (BRASIL, 2014).

Ao se verificar o propósito explícito nos documentos oficiais do estado brasileiro, elaborados e aprovados em forma de lei, principalmente após a Conferência em Paris (1998), resta analisar como essas definições acabaram por transferir modelos, critérios e indicadores para ser avaliada a internacionalização em nosso país e outros possíveis.

\section{TRANSFERÊNCIA INTERNACIONAL DE PROJETOS EDUCACIONAIS}

Em todo o mundo, a universidade parece estar em crise constante, diante das rápidas mudanças no campo da economia, da cultura e da política, provocadas a partir da globalização. Como bem coloca Mello (2011, p. 25): 
[...] os vínculos e interdependências globais dos circuitos econômicos/ financeiros e dos espaços de decisão política; as redes mundiais de comunicação; as estruturas transnacionais de produção e circulação de bens e mercadorias; as facilidades de deslocamento dos atores sociais (indivíduos e grupos) por redes conectadas de transportes; os reencaixes supranacionais de identidade social; a disseminação do inglês como língua universal e outros tantos fatores contribuem para que se esfumacem - ou pelo menos borrem -, everywhere, as antigas fronteiras e territorialidades que haviam demarcado com certa rigidez, ao longo da modernidade, os papéis de cada instituição na divisão do trabalho social.

Nesse contexto de globalização e de mudanças no cenário econômico e social, a solução dos problemas que surgem na fronteira do século XXI será determinada por uma amplitude de perspectivas na visão da "sociedade do futuro" e pela função que se determine à educação, em geral, e à ES, em particular, na qual apresenta como uma das justificativas o fato de que no limiar de um novo século:

[...] há uma demanda sem precedentes e uma grande diversificação na educação superior, bem como maior consciência sobre a sua importância vital tanto para o desenvolvimento sociocultural e econômico como para a construção do futuro, diante do qual as novas gerações deverão estar preparadas com novas habilitações, conhecimentos e ideais. (UNESCO, 1998, s.p.).

Ainda em seu preâmbulo, o documento relata que "a cooperação e o intercâmbio internacional são os caminhos principais para promover o avanço da educação superior em todo o mundo.” (UNESCO, 1998, s.p.).

Em acordo com o estabelecido na Conferência em Paris (1998), e transferido para os países em desenvolvimento, o Brasil recebe as determinações e elabora o Instrumento de Avaliação Institucional Externa (INEP, 2017) com intuito de avaliar as políticas institucionais para a internacionalização (indicador 3.6) que verifica se a IES "apresenta atividades voltadas para programas de cooperação e intercâmbio" (INEP, 2017, p. 18).

Segundo o Instrumento de Avaliação Institucional Externa, "programa de cooperação" significa "qualquer programa que imprime uma ação conjunta para uma finalidade, um objetivo em comum entre instituições de ensino superior com instituições estrangeiras ou nacionais, promovendo parcerias acadêmicas, podendo ser bilaterais ou multilaterais." (INEP, 2017, p. 18).

Nessa perspectiva, a Conferência Mundial sobre a Educação Superior no Século XXI: Visão e Ação, pode ser considerada "chave", uma vez que os países participantes, desenvolvidos e em desenvolvimento, do Norte e do Sul, acordaram e formalizaram compromissos a cumprir, apresentando três grandes pontos estratégicos: o primeiro, Missões e Funções da Educação Superior; o 
segundo, Formando uma Nova Visão da Educação Superior; e o terceiro, Da Visão à Ação. A seguir, analisaremos como foram transferidas ideias e ações a serem seguidas pelos países signatários.

No subtítulo "Formando uma Nova Visão da Educação Superior", o art. $10^{\circ}$ sinaliza como agentes principais no processo, o "pessoal de educação superior e estudantes". O artigo determina que "deve ser dada mais importância à experiência internacional", para tanto os países devem elaborar "uma política vigorosa de desenvolvimento de pessoal" para ascender à experiência internacional, para isso pressupõe algumas providências adequadas, conforme o artigo orienta:

[...] atualizar e melhorar as habilidades pedagógicas, por meio de programas apropriados de desenvolvimento de pessoal, estimulando a inovação constante dos currículos e dos métodos de ensino e aprendizagem, que assegurem as condições profissionais e financeiras apropriadas ao profissional, garantindo assim a excelência em pesquisa e ensino. (UNESCO, 1998, s.p.).

Ao determinar sobre o "estímulo à inovação constante dos currículos", o Instrumento de Avaliação Institucional Externa (INEP, 2017, p. 15), em seu indicador 3.1, considera "a atualização curricular sistemática" como critério de análise a ser avaliado. Também no PNE (2014), na meta 14, estratégia 14.11, há uma resposta às políticas transferidas quando no Brasil somos orientados a "ampliar o investimento em pesquisas com foco em desenvolvimento e estímulo à inovação, bem como incrementar a formação de recursos humanos para a inovação."

No subtítulo "Da Visão à Ação", no seu art. 11, sobre "Avaliação da qualidade", o artigo esclarece inicialmente sobre a visão dos participantes da conferência sobre qualidade na ES como sendo "um conceito multidimensional que deve envolver todas as suas funções e atividades: ensino e programas acadêmicos, pesquisa e fomento da ciência, provisão de pessoal, estudantes, edifícios, instalações, equipamentos, serviços de extensão à comunidade e o ambiente acadêmico em geral" (UNESCO, 1998, s.p.). Declara, ainda, que para uma ES ser considerada de qualidade, requer que "seja caracterizada por sua dimensão internacional: intercâmbio de conhecimentos, criação de redes interativas, mobilidade de professores e estudantes, e projetos de pesquisas internacionais."

Segundo o Instrumento de Avaliação Institucional Externa (INEP, 2017), a mobilidade docente e discente é o: 
[...] processo que possibilita ao discente/docente vinculado a uma IES estudar/ trabalhar em outra, estabelecendo vínculo temporário com a IES receptora. Compreende uma cooperação entre instituições de ensino Superior, que confere aos alunos/professores a oportunidade de complementar seus estudos e enriquecer a sua formação, tanto por meio dos componentes curriculares, como também pela experiência de entrar em contato com ambientes acadêmicos diferentes. (p. 38)

Assim, novamente em resposta as determinações internacionais, outro critério de análise avaliativo para as IES brasileiras é a mobilidade de docentes e discentes - indicador 3.1 (INEP, 2017).

O Instrumento de Avaliação Institucional Externa esclarece que programa de intercâmbio significa "qualquer programa que possibilita ao aluno vinculado a uma IES estudar em outra, estabelecendo vínculo temporário na instituição internacional." (INEP, 2017, p. 41).

Ainda no art. 11, item c (UNESCO, 1998, s.p), volta-se a sugerir que para que uma ES seja de qualidade certos componentes são relevantes, como "a mobilidade entre países, instituições de educação superior, os estabelecimentos de educação superior e o mundo do trabalho, assim como entre estudantes de cada país e de distintos países." Sobre a qualidade da ES, o artigo apresenta componentes como a mobilidade entre países, instituições e estabelecimento de ES e o mundo do trabalho e complementa dizendo que a mobilidade é um componente também para estudantes de cada país e de países distintos (UNESCO, 1998, s.p.).

"O potencial e o desafio de tecnologia" é o subtítulo que apresenta o art. 12 e menciona que as IES devem aproveitar o potencial das tecnologias de informação e comunicação (TIC), "cuidando da qualidade e mantendo níveis elevados nas práticas e resultados da educação, com um espírito de abertura, igualdade e cooperação internacional" (UNESCO, 1998, s.p.), visando "facilitar, por meio da cooperação internacional, a identificação dos objetivos e interesses de todos os países, particularmente os países em desenvolvimento, o acesso equitativo e o fortalecimento de infraestruturas neste campo e da difusão destas tecnologias por toda a sociedade."

O documento segue em seu art. 15 sobre "compartilhar conhecimentos teóricos e práticos entre países e continentes” (UNESCO, 1998, s.p.), orientando para o princípio da solidariedade e uma autêntica parceria entre as IES em todo o mundo, e ressalta ainda que para que isso ocorra será:

[...] crucial para que a educação e a formação em todos os âmbitos motivem uma compreensão melhor de questões globais e do papel de uma direção democrática e de recursos humanos qualificados para a solução de tais questões, além da necessidade de se conviver com culturas e valores diferentes. 
Alerta para a importância de que "o domínio de múltiplos idiomas, os programas de intercâmbio de docentes e estudantes, e o estabelecimento de vínculos institucionais para promover a cooperação intelectual e científica devem ser parte integrante de todos os sistemas de ES.” (UNESCO, 1998, s.p.).

A internacionalização é condição de qualidade para a ES, e tem como princípio a cooperação entre países com base na solidariedade, no reconhecimento, no apoio mútuo, na autêntica parceria, na importância do compartilhamento de conhecimento teóricos e práticos e na colaboração em longo prazo.

Ao se referir sobre a cooperação, a prioridade está nos programas de formação para os países em desenvolvimento, como para centros de excelência, organizados em redes regionais e internacionais e cursos de curto prazo no exterior (especializados ou intensivos), aborda a importância de compartilhar conhecimentos teóricos e práticos em nível internacional, guiando as relações entre as IES, entre os países desenvolvidos, em desenvolvimento e os menos desenvolvidos. Já sobre a colaboração em longo prazo, refere-se que ocorra entre os países do hemisfério Norte e hemisfério Sul e entre os países do sul-sul global (UNESCO, 1998).

Nos indicadores do Sinaes, especificamente no indicador sobre políticas institucionais, ações de estímulo à produção discente e à participação em eventos (graduação e pós-graduação), explicita-se, nos critérios de análise avaliativos, que:

[...] as políticas institucionais e ações de estímulo possibilitam apoio financeiro ou logístico para a organização e participação em eventos na IES e de âmbito local, nacional ou internacional, e apoio à produção acadêmica discente e à sua publicação em encontros e periódicos nacionais e internacionais. (INEP, 2017, p. 20).

O artigo 15 da Declaração em Paris afirma que "a dimensão internacional deve estar presente nos planos curriculares e nos processos de ensino e aprendizagem.” (UNESCO, 1998, s.p.)

A declaração indica a internacionalização como condição de qualidade para a ES e demonstra a preocupação sobre a "perda de quadros", ao "ganho de talentos" científicos, e o texto explicita que "é preciso pôr fim à 'perda' de talentos científicos, já que ela vem privando os países em desenvolvimento e os países em transição de profissionais de alto nível, necessários para acelerar seu progresso socioeconômico." (UNESCO, 1998, s.p.).

Uma prioridade é criar um ambiente que atraia e mantenha o capital humano qualificado, entendido esse como especialistas altamente treinados, e investigadores muito competentes. Para alcançar essa prioridade, são necessárias políticas nacionais ou acordos internacionais que facilitem o retorno aos seus países de origem (UNESCO, 1998). 
Ao mesmo tempo, devem ser dirigidos esforços para que se implemente um processo de "ganho" de talentos por programas de colaboração que favoreçam, em virtude de sua dimensão internacional, a criação e o fortalecimento de instituições que facilitem a utilização plena das capacidades endógenas (UNESCO, 1998).

A partir do apresentado até aqui, pode-se entender como o Brasil absorve, enquanto país em desenvolvimento, as ideias transferidas das agências internacionais, e nesse caso está evidente que essas políticas avaliativas recaem sobre as IES, esperando destas uma adaptação a tais exigências. Segundo Lyotard (2009, p. 5):

[...] há alguns anos, o conhecimento em nosso tempo é produzido para ser vendido. Assim, se o departamento de educação de determinada universidade desenvolve certo conhecimento sobre como tornar uma escola (ou um sistema educacional distrital ou nacional) mais eficiente e eficaz, deve vender esse conhecimento no mercado de forma a contribuir com o desempenho da organização.

O manuscrito apresenta um trabalho cuidadoso de garimpo e revisão que analisa a declaração produzida na conferência (UNESCO, 1998), sinalizando cada uma das exigências elaboradas no evento e busca nos documentos em questão no estudo, onde, e de que forma essas exigências foram traduzidas para regrar a ES brasileira.

Nessa análise, está evidente que a ênfase está na qualidade da ES, alertando para o fato de que para garantir a qualidade é necessário que as IES priorizem: programas de cooperação com a criação de redes interativas; intercâmbio de conhecimentos; a mobilidade de professores e estudantes entre países; a inovação constante dos currículos e dos métodos de ensino e aprendizagem; e projetos de pesquisas internacionais entre instituições de educação superior.

A seguir, pode-se verificar, sobre o recorte do texto da Unesco, a ênfase na estatística da análise textual por similitude. 


\section{Figura 1 - Recorte texto Educação Superior UNESCO (1998):}

Análise de Similitude

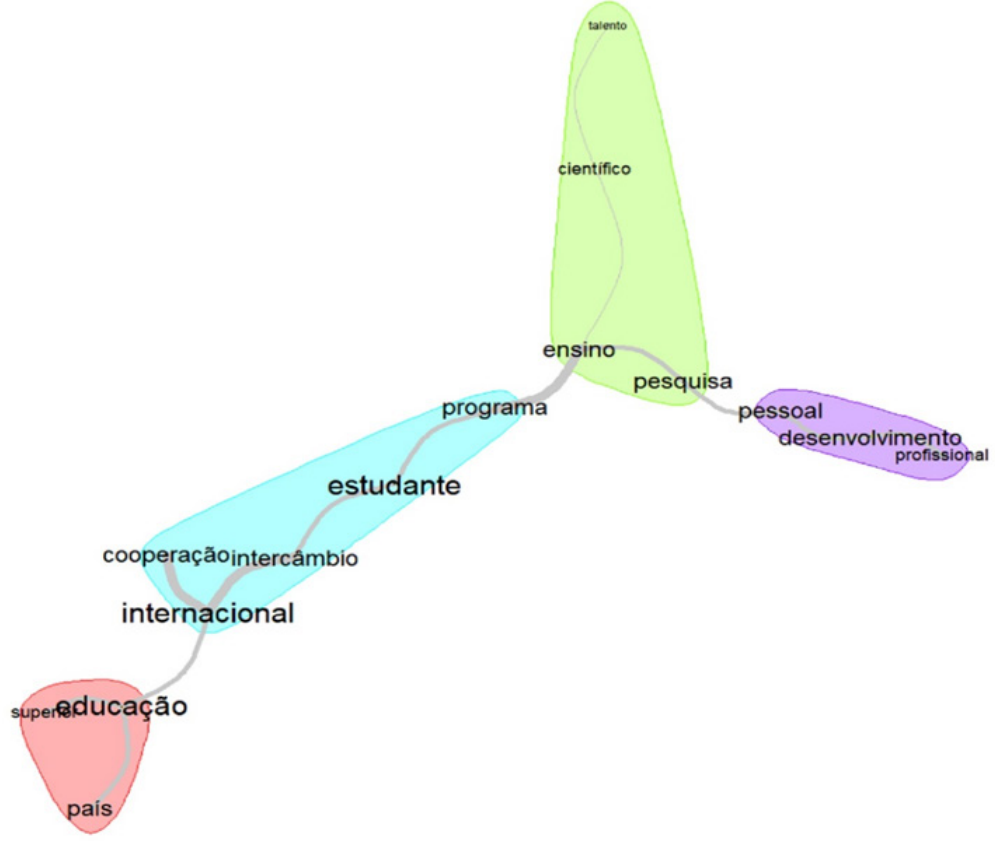

Fonte: Elaborado pelos autores - Iramuteq.

A análise de similitude apresentada na Figura 1 possibilita o entendimento de que no recorte realizado no texto da Unesco, em questão, os termos "internacional" e "estudante" são centrais e estão relacionados no mesmo grupo com "intercâmbio, cooperação e programa". Os termos "internacional" e "estudante" estão relacionados em especial com um campo mais isolado que é "educação superior". O campo central menciona "programa” bastante próximo a pesquisa, inicialmente, e ensino logo após, mas não está relacionado com o campo dos termos "pessoal e desenvolvimento profissional". Este último grupo está voltado para ensino e pesquisa, mas pouco relacionado com "estudante".

Assim, evidencia-se que o texto da Unesco apresenta maior interesse e recorrência dos termos: internacionalização, intercâmbio de estudantes e programas de cooperação. 


\section{Figura 2 - Recorte sobre Educação Superior INEP (2017): Análise de Similitude}
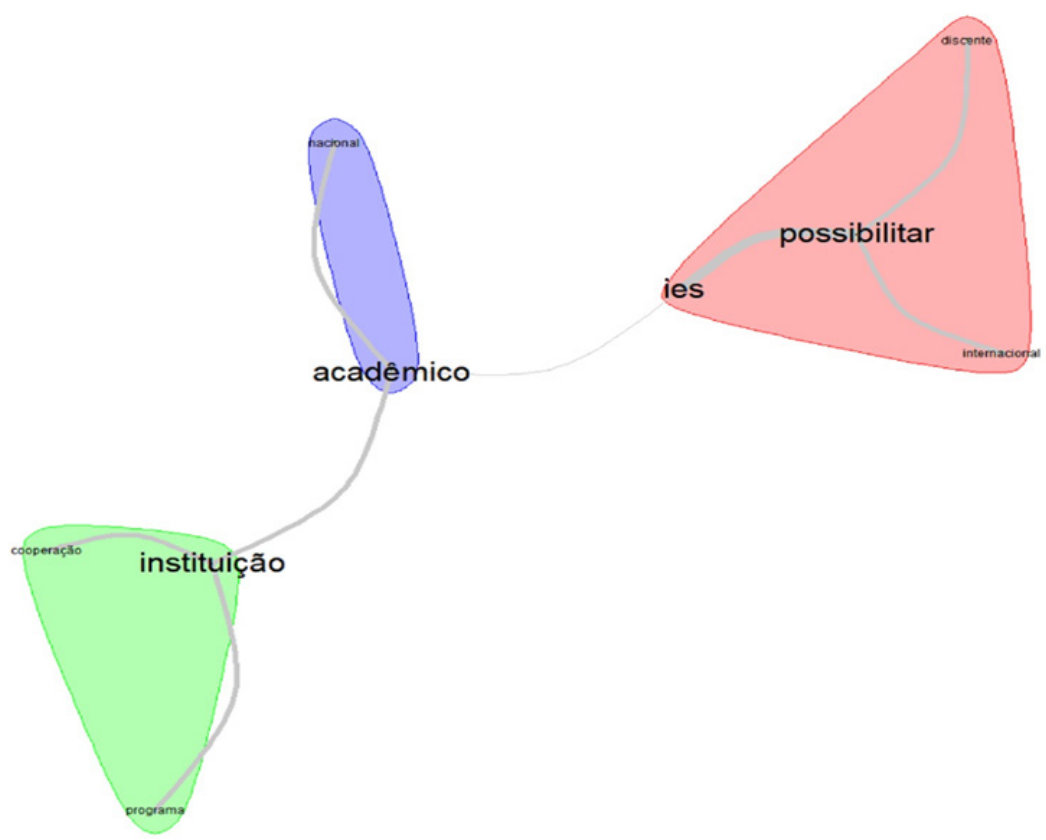

Fonte: Elaborado pelos autores - Iramuteq.

Já na análise de similitude apresentada na Figura 2, relativa ao texto do Inep (2017), pode-se verificar a centralidade do termo "acadêmico" no discurso do texto, contendo no mesmo campo o termo "nacional". Relaciona-se de certa forma com um segundo campo que apresenta o termo "instituição" como central, relacionando-se com os termos "programa" e "cooperação". Já no outro campo, ligado ao termo "acadêmico", encontram-se os termos "internacional" e "discente".

Para o instrumento do Inep, pode-se verificar que o estudante é central no texto. Nota-se ainda que a IES, por um lado precisa possibilitar a internacionalização e, por outro, necessita de programas de cooperação. 
Figura 3 - Recorte dos textos sobre ES da UNESCO (1998) e INEP (2017): Análise de Similitude

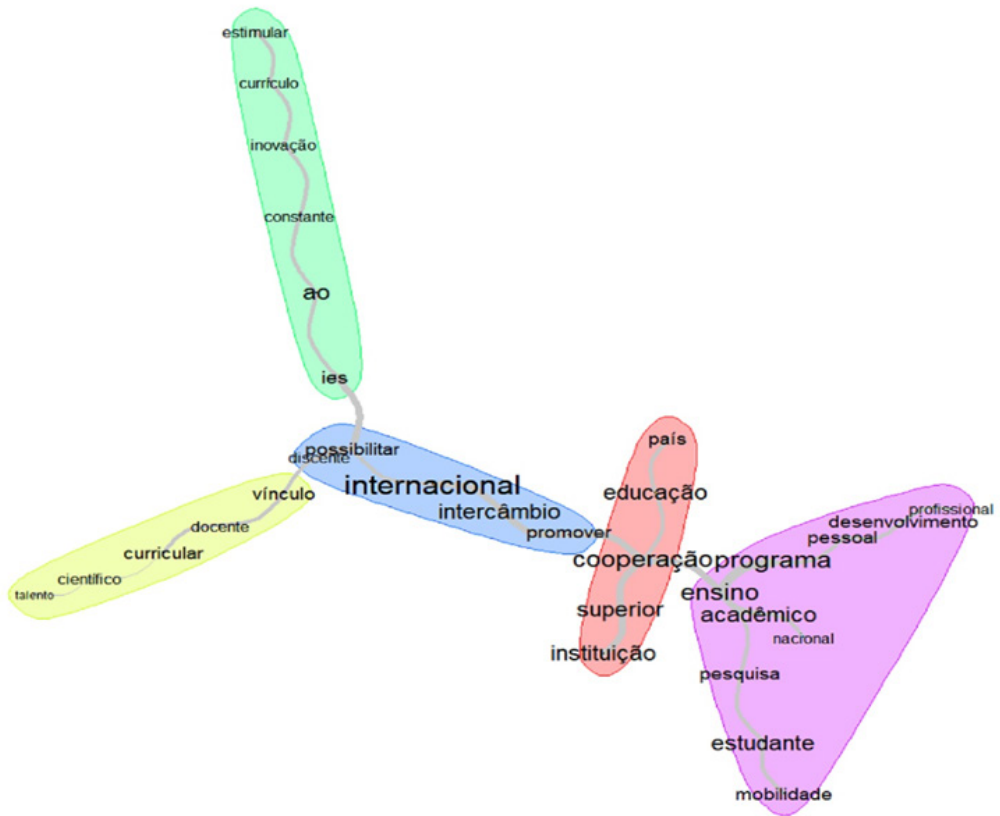

Fonte: Elaborado pelos autores - Iramuteq.

Ao juntarmos os textos da Unesco e do Inep, temos a centralidade e maior recorrência do termo "internacional" por ser a temática deste estudo, e que se confirma a partir do software, que facilita a análise por similitude. Esse grupo está inserido no mesmo campo que os termos relacionados mais fortemente com: "intercâmbio" e "discente". Pode-se verificar ainda três outros campos relacionados em primeira ordem com o termo "internacional", que são: "vínculo", "docente" e "currículo". Em outro campo, encontra-se a ocorrência de "cooperação", "país" e "educação superior". No terceiro campo, a maior ocorrência é dos termos "estimular", "inovação" e "constante". Um outro campo ainda não mencionado, pois encontra-se ligado ao campo da "internacional", por $2^{a}$ ordem, são os termos "programa", "ensino acadêmico", "desenvolvimento pessoal" e "mobilidade". 


\section{CONSIDERAÇÕES FINAIS}

Pelas análises realizadas, buscou-se evidenciar, o quanto a Conferência Mundial sobre a Educação Superior no Século XXI: Visão e Ação, realizada em Paris (1998), foi alavancadora dos processos e ideias sobre a educação superior, transferidas para os países em desenvolvimento nos anos subsequentes.

Considerando essa multiplicidade de olhares, uma das contribuições desta pesquisa

está relacionada ao fato de colocar em discussão as políticas avaliativas que são transferidas para diferentes contextos, com pouca ou nenhuma preocupação com as distintas culturas, com a história dos movimentos dos professores, com os recursos disponíveis para implementação de tais políticas, com as diferentes missões das instituições de ensino superior.

As decisões das agências multilaterais são transferidas aos países em desenvolvimento e os países, por sua vez, absorvem as ideias com pouca discussão sobre os critérios para efetivação. Esse processo bilateral, com benefícios na maior parte das vezes unilaterais, promovem dificuldades para os países se adaptarem, seja no âmbito econômico, cultural, social, etc.

Essas exigências nem sempre são apoiadas financeiramente pelos países que adotam tais políticas de internacionalização, recaindo sobre as instituições, os gestores institucionais e os professores, o compromisso de efetivar os acordos. Se uma instituição, por motivos variados, não consegue responder às exigências, poderá ser duramente punida no processo avaliativo institucional. A partir dessa afirmativa, considera-se necessário realizar estudos que possam discutir os impactos das políticas de avaliação sobre a autonomia institucional.

Considerando esses pontos, entendemos que compreender esse processo e problematizar a forma e as estratégias institucionais de diferentes IES seja oportuno nesse momento e que possa contribuir para além da mobilidade docente e discente. Desenvolver políticas institucionais de internacionalização da ES é importante, mas torna-se fundamental que sejam situadas, refletidas e assumidas conscientemente, tanto por aqueles que as produzem, como pelos que de fato as farão acontecer, ou seja: as IES, os gestores institucionais, os professores, e os estudantes. 


\section{REFERÊNCIAS}

BARTELL, Marvin. Internacionalization of universities: a university-culturebased framework. Higher Education. Manitoba: Winnipeg, p. 37-52, 2003.

BEECH, Jason. Quem está passeando pelo jardim global? Agências educacionais e transferência educacional. In: COWEN, Robert; KAZAMIAS, Andreas M.; UNTERHALTER, Elaine (Orgs.). Educação comparada: panorama internacional e perspectivas. Brasília: Unesco, 2012. v. 1.

BRASIL. [Constituição (1988)]. Constituição da República Federativa do Brasil de 1988. Brasília, DF: Presidência da República, [2016]. Disponível em: http://www.planalto.gov.br/ccivil_03/Constituicao/ Constituiçao.htm. Acesso em: 28 jul. 2019.

BRASIL. Ministério das Relações Exteriores. Coleção Mundo Afora, Brasília, n. 9, set. 2012. Disponível em: https://sistemas.mre.gov.br/kitweb/datafiles/Oslo/ pt-br/file/09_Cultural/09-10-Mundo_Afora_09.pdf. Acesso em: 15 out. 2019.

BRASIL. Decreto no 591, de 6 de julho de 1992. Pacto Internacional dos Direitos Econômicos, Sociais e Culturais. Brasília, DF, 1992. Disponível em: http://www.planalto.gov.br/ccivil_03/decreto/1990-1994/d0591.htm. Acesso em: 28 jul. 2019.

BRASIL. Lei $\mathbf{n}^{\circ}$ 13.005/2014. Plano Nacional de Educação(PNE). Brasília, DF, 2014. Disponível em: http://pne.mec.gov.br/18-planos-subnacionais-deeducacao/543-plano-nacional-de-educacao-lei-n-13-005-2014. Acesso em: 28 jul.2019.

DELORS, Jacques. Educação um Tesouro a Descobrir. Comissão Internacional sobre Educação para o Século XXI. 1995. Disponível em: https://unesdoc. unesco.org/ark:/48223/pf0000109590_por. Acesso em: 28 jul. 2019.

DIAS SOBRINHO, José. Educação Superior, globalização e democratização. Revista Brasileira de Educação, v. 28, p. 164-173, 2005. 
INSTITUTO NACIONALDE ESTUDOS E PESQUISAS ANÍSIO TEIXEIRA (Inep). Instrumento de Avaliação Institucional Externa (2017). Brasíliam DF, 2017. Disponível em: http://download.inep. gov.br/educacao_superior/ avaliacao_institucional/instrumentos/2017/IES_recredenciamento.pdf. Acesso em: 28 jul. 2019.

LYOTARD, Jean-François. A Condição Pós-Moderna. 12. ed. Rio de Janeiro: Editora José Olímpio, 2009.

MAINARDES, Jefferson. Abordagem do ciclo de políticas: uma contribuição para a análise de políticas educacionais. Educação e Sociedade, Campinas, v. 27, n. 94, p. 47-69, jan./abr. 2006. Disponível em: http://www.scielo.br/pdf/es/ v27n94/a03v27n94.pdf. Acesso em: 15 out. 2019.

MAYOR, Frederico; SEMA Tanguiane. Unesco: an ideal in action; the continuing relevance of a visionary text. Paris: Unesco, 1997.

MELLO, Alex Fiúza de. Globalização, sociedade do conhecimento e educação superior: os sinais de Bolonha e os desafios do Brasil e da América Latina. Brasília: Editora Universidade de Brasília, 2011.

MOROSINI, Marília Costa. Estado do conhecimento sobre internacionalização da educação superior: conceitos e práticas. Educar, Curitiba, n. 28. p. 107-127, 2006.

ORGANIZAÇÃO DAS NAÇÕES UNIDAS (ONU). Declaração Universal dos Direitos Humanos. Disponível em: https://www.ohchr.org/EN/UDHR/ Pages/Language.aspx?LangID=por. Acesso em: 28 jul. 2019.

ORGANIZAÇÃO DAS NAÇÕES UNIDAS (ONU). Desenvolvimento sustentável. Disponível em: https:// nacoesunidas.org/numero-de-universitariosdobrou-no-mundo-entre-2000-e-2014-diz-unesco/. Acesso em: 28 jul. 2019.

ORGANIZAÇÃO DAS NAÇÕES UNIDAS PARA A EDUCAÇÃO, A CIÊNCIA E A CULTURA (Unesco). Conferência Internacional para Educação Superior para o Século XXI: visão e ação. Paris, 1988. Disponível em: http://www.direitoshumanos.usp. br/index.php/Direito-aEduca \%C3\%A 7\%C3\%A3o/declaracao-mundial-sobre-educacao-superior-noseculo-xxi-visao-e-acao.html. Acesso em: 28 jul. 2019. 


\section{Marialva Moog Pinto}

Docente do Mestrado em Educação da Universidade do Planalto CatarinenseUNIPLAC. Doutora em Educação - UNISINOS (2010 - CAPES 7). Pesquisadora da Rede Estudos da America Latina sobre Educação Superior (REALES), com o Projeto NEIES- Mercosul (representando o Brasil, juntamente com Chile, Colômbia, Paraguai, Uruguai e Argentina - 2018-2021). Membro do Grupo Internacional de Estudos e Pesquisas em Educação Superior - GIEPES/ Unicamp. Avaliadora de Cursos do INEP. E-mail: marialvamoog@hotmail.com

\section{Gildo Volpato}

Doutor em Educação pela Universidade do Vale do Rio dos Sinos, UNISINOS (2007) e pós doutor em Educação pela UFSC (2018). Docente do Programa de Pós Graduação em Educação, PPGE - Mestrado e Doutorado em Educação da Universidade do Extremo Sul Catarinense, UNESC. Reitor da UNESC (julho de 2009 a junho de 2017). Atualmente é Conselheiro Titular do Conselho Estadual de Educação de Santa Catarina exercendo a Vice Presidência. E-mail: giv@ unesc.net

Recebido em: 23/08/2020

Aprovado em: 26/04/2021 